Editorial

\title{
The Inclusiveness of Social Rights: The Case of Leave Policies
}

\author{
Sonja Blum ${ }^{1, *}$ and Ivana Dobrotić ${ }^{2,3}$ \\ ${ }^{1}$ Institute of Political Science, University of Hagen, 58084 Hagen, Germany; E-Mail: sonja.blum@fernuni-hagen.de \\ 2 Department of Social Policy and Intervention, University of Oxford, Oxford, OX12ER, UK; \\ E-Mail: ivana.dobrotic@spi.ox.ac.uk \\ ${ }^{3}$ Faculty of Law, University of Zagreb, 10000 Zagreb, Croatia \\ * Corresponding author
}

Submitted: 16 May 2021 | Published: 11 June 2021

\begin{abstract}
This thematic issue aims to deepen the theoretical as well as empirical knowledge on the inclusiveness of social rights, focussing on the revelatory case of parenting-related leave policies. This editorial defines (leave) inclusiveness and discusses extant research on varying entitlements and eligibility criteria in the field of parenting leaves. It summarises the conceptual, methodological, and empirical contributions made by the articles in the thematic issue and closes with a research outlook.
\end{abstract}

\section{Keywords}

eligibility criteria; entitlement; inclusiveness; leave policy; parental leave; selectivity; universalism

\section{Issue}

This editorial is part of the issue "The Inclusiveness of Social Rights: The Case of Parental Leave Policies" edited by Sonja Blum (University of Hagen, Germany) and Ivana Dobrotić (University of Oxford, UK / University of Zagreb, Croatia).

(C) 2021 by the authors; licensee Cogitatio (Lisbon, Portugal). This editorial is licensed under a Creative Commons Attribution 4.0 International License (CC BY).

\section{Introduction}

As is widely recognized, welfare states may both reduce or reinforce existing inequalities to different extents, and social programmes may have stratifying and genderizing effects (Esping-Andersen, 1990; Orloff, 1993). This is primarily related to the design of welfare states and the differences in entitlement principles related to social rights, such as employment, citizenship, or marriage. Moreover, the conditions under which social rights may be exercised (eligibility criteria) can be more or less strict. The effect of various social programmes may thus relate to the extent to which countries rely on universal principles for granting social rights, making them more or less inclusive, as well as policy implementation. Parenting leaves are particularly telling regarding the inclusiveness of social rights, that is, the extent to which the rights are granted to all (see, e.g., Dobrotic \& Blum, 2020; Wong, Jou, Raub, \& Heymann, 2019). Yet the compara- tive leave policy literature has usually analysed leave generosity (especially leave duration and leave benefits levels), while less was known about leave eligibility and corresponding inequalities.

With this thematic issue, we aim to deepen the theoretical as well as empirical knowledge on the inclusiveness of leave policies and strengthen new lines of research. The issue contains eleven articles, four of them focusing on conceptual and/or methodological contribution to the field, thinking through questions of inclusion in leave policy design and how to measure and conceptually grasp entitlements to social rights. Seven articles focus on empirical contributions, investigating the drivers, patterns, and outcomes of varying leave inclusiveness in individual countries or in a comparative perspective. Before outlining these contributions further, we first turn to definitions of (leave) inclusiveness and briefly address extant research on eligibility to parenting leaves. 


\section{The Inclusiveness of Leave Policies}

\subsection{Defining Inclusiveness of Social Rights}

There are three key dimensions of social rights and respective policy design, namely entitlement principle, eligibility criteria, and benefit scope (Blank, 2011; Clasen \& Clegg, 2007). Benefit scope denotes what social rights are available, especially their generosity. The first two dimensions-entitlement principles and eligibility criteria-come to the fore when we ask who is granted access to social rights and when. Those two dimensions are telling about the inclusiveness of social rights (cf. Dobrotić \& Blum, 2019, 2020). Indeed, social rights may be available universally for all who are affected by a specific social risk (such as old-age, unemployment, parenthood), or eligibility may be restricted to certain groups (e.g., only employees) or conditions (e.g., excluding those with short-term contracts; cf. Anttonen, Haikio, Stefansson, \& Sipila, 2012; Budowski \& Künzler, 2020). Against this backdrop, and for the risk of parenthood, 'inclusiveness' relates to the degree to which rights are available to all parents irrespective of (forms or previous length of) their employment, citizenship, or other criteria based on family, gender, or further personal characteristics. The connections between inclusiveness and the scope (particularly generosity) of rights are also important, especially as different 'status' groups may be granted rights of differing generosity. Finally, the implementation of social rights can be relevant to consider, as 'practice' may bring about inequalities that do not exist 'on paper.'

\subsection{Inclusiveness and Leave Policies}

There are different types of leave policies for carers. If we focus on leaves available for parents, an established distinction is between maternity, paternity, and parental leave, as well as leave for children who are ill (Koslowski, Blum, Dobrotić, Kaufman, \& Moss, 2020). Borders between these types can be fuzzy, and their design country-specific. Yet the distinctions are still useful for comparative purposes.

Research has shown that there are large differences within and between countries regarding who is eligible to take leave or receive (certain) leave benefits, varying between different family forms, mothers and fathers, or according to parents' employment status. For example, studies pointed to gender inequalities in access to leave rights (e.g., O’Brien, 2009; Ray, Gornick, \& Schmitt, 2010), while McKay, Mathieu, and Doucet (2016) showed that strict employment-related eligibility criteria in parts of Canada exclude a large share of mothers from access to maternity or parental benefits, especially those in atypical or less secure employment. Wong et al. (2019, p. 525) have demonstrated that "same-sex female and different-sex couples receive equal durations of leave in the majority of" (though not all) OECD countries, yet "same-sex male couples often receive shorter durations of paid parental leave." A recent report from the European Institute for Gender Equality (2020) concludes that only few European countries grant universal access to parental leave. In effect, (varyingly large) proportions of parents remain ineligible, especially those who are "economically inactive, in non-standard types of employment, such as self-employment, and [who] have been in their job for less than 12 months" (European Institute for Gender Equality, 2020, p. 24).

In our recent work (Dobrotić \& Blum, 2019, 2020) we investigated the inclusiveness of parental leave benefits by considering entitlement principles and eligibility criteria attached to them. We showed that entitlement principles in leave policies can rest on citizenship (and/or residency) or employment, while eligibility criteria can be selective or universal. On this basis, we distinguished four ideal-type approaches to how parental leave rights are granted (in-)dependent of parents' labour market position: a universal parenthood model, a selective parenthood model, a universal adult-worker model, and a selective adult-worker model (Dobrotić \& Blum, 2019). We then created an eligibility index to measure the inclusiveness of parental leave benefits, that is, the extent to which benefits are available to all parents (Dobrotić \& Blum, 2020). By applying this index to parental leave benefits development in 21 European countries, we showed that the importance of employment-based benefits and gender-sensitive policies increased in recent years. However, eligibility criteria have remained stable, which-considering labour market trends such as increasing precariousnessindicates that "fewer parents may fulfil the conditions for employment-based benefits" (Dobrotić \& Blum, 2020, p. 588). All this asks for a deeper look into the inclusiveness of leave rights, addressed by the contributions in this thematic issue.

\section{Contributions to the Thematic Issue}

The thematic issue opens with four articles that put the primary focus on conceptual and methodological issues. Doucet's (2021) article 'unthinks' and 'rethinks' the binary care-and-work metanarrative that underlies parenting leaves, pointing at conceptual narratives that could provide the 'scaffolding' for more inclusive leave policies going beyond 'employment policy' towards care and work policy. Her suggested elements of a new conceptual narrative come timely for thinking through post-pandemic leave (re)conceptualization. Otto, Bartova, and Van Lancker (2021) focus on how generosity (and inclusiveness) of leave policies has been measured, including indicators of social spending, social rights, and benefit receipt. Their contribution illustrates "how the operationalisation of leave generosity by means of different indicators can lead to different rankings, interpretations and qualifications of countries," pointing at the importance of well-thought choice 
of indicators in policy studies or research (Otto et al., 2021, p. 238). Koslowski (2021) then focuses on how to capture-and quantify-the 'gender gap' in parenting leave entitlements. Focusing on well-paid individual leave entitlements to maternity, paternity and parental leave, she develops a 'gender gap indicator' aimed to contribute to a better understanding of leave inclusiveness for men as compared to women. Finally, Kurowska (2021) reflects on our inclusiveness operationalization and eligibility index, complementing it by the indicators of 'contextualized' inclusiveness, that is, inclusiveness embedded in the countries' socio-economic contexts.

The next four contributions in the thematic issue put the concepts and theoretical considerations to the test empirically in a comparative perspective. Son and Böger (2021) investigate the inclusiveness of maternity leave rights over 120 years and across five continents. Thus, for the first time and based on new data, they provide an encompassing historical and comparative account of maternity leave's beginnings and trajectories, focusing on eligibility and pointing at an important role of the political empowerment of women in increasing the paid maternity leave inclusiveness. Whitehouse and Nakazato (2021) compare Australia and Japan, representing distinctive manifestations of a selective, employment-based entitlement model. Their differences are illustrated focusing on three dimensions of social equality (inclusion, gender equality, redistribution) pointing at trade-offs between inclusion and gender differentiation and highlighting funding systems as drivers of policy difference within employment-based entitlement systems. Nygård and Duvander (2021) investigate political discourses on parental leave in a comparative case study of Finland and Sweden. They show that gender-equality ideas have been more influential in the Swedish discourse, whereas in Finland, social inclusion, and notably the rights of same-sex parents, became more prominent. Rostgaard and Ejrnæs (2021) study the Danish case-'exceptional' by its lack of a statutory father's quota-in Nordic comparison. Exploring Danish fathers' lower leave take-up comparatively, they conclude that attitudes in this case matter less than the institutional conditions, particularly for Danish fathers with lower education.

The final three articles provide an in-depth investigation of single cases of particular relevance regarding eligibility in leave policies. First, Marynissen, Wood, and Neels (2021) develop an individual-level indicator of leave eligibility in Belgium, using detailed register data. They show that a considerable share of mothers does not meet the eligibility criteria and are structurally excluded from parental leave in Belgium, and how a reconsideration of eligibility criteria may be crucial to improve the inclusiveness of parental leave policies. Moring and Lammi-Taskula (2021, p. X) focus on Finland, exploring reforms "questioning the hegemony of the birth mothers" and aiming to broaden eligibility for paid parental leave to go beyond biological parents. They show how in a stepwise process, reforms have focused on promoting gender equality, equality between diverse families, and-most recently-equality between all children in the 'right to leave.' Uzunalioglu, Valentova, O'Brien, and Genevois (2021) investigate the conditions under which expanded eligibility translates into increased take-up. Studying Luxembourg's parental-leave reform of 2016, which extended eligibility to marginal-part-time working parents, they demonstrate how mothers from this group increased take-up. Outreach to marginal-part-time employed fathers and parents with an immigrant background, however, remained very limited.

\section{Outlook}

While gender inequalities in access to parenting leaves have a more longstanding tradition and advanced state of knowledge, other inequalities-such as those related to employment history, citizenship, migration or family status-have only recently come to the fore. As Doucet (2021, p. X) highlighted, more and more parents around the globe cannot meet eligibility criteria for leave rights due to developments such as the rise of the platform economy and precarious employment, and the issue of inclusiveness has "become even more urgent since the COVID-19 pandemic." Against this backdrop, this thematic issue aims to strengthen these new lines of research, focusing on conceptual, methodological and empirical contributions. Many silent cleavages remain embedded in leave policy design, which ask for further unpacking and elaboration in future research. Withincountry (and not only cross-country) differences regarding unequal access to leave rights deserve attention as well as conceptual and methodological rethinking in the future.

\section{Acknowledgments}

We are grateful to the editorial assistance at Social Inclusion, particularly from Mariana Pires, for their careful guidance through this thematic issue's publication. Our thanks go to all the authors as well, for their contributions and determination in moving research on inclusiveness of parenting leaves forward. Ivana Dobrotić's research is part of a project that has received funding from the European Union's Horizon 2020 Research and Innovation Programme under grant agreement No786826.

\section{Conflict of Interests}

The authors declare no conflict of interests.

\section{References}

Anttonen, A., Haikio, L., Stefansson, K., \& Sipila, J. (2012). Universalism and the challenge of diversity. In A. Anttonen, L. Haikio, \& K. Stefansson (Eds.), Welfare state, 
universalism and diversity (pp. 1-15). Cheltenham: Edward Elgar.

Blank, F. (2011). Soziale Rechte 1998-2005: Die Wohlfahrtsstaatsreformen der rot-grünen Bundesregierung [Social rights 1998-2005. The welfare state reforms of the red-green government]. Wiesbaden: VS.

Budowski, M., \& Künzler, D. (2020). Universalism in social policies: A multidimensional concept, policy idea or process. Social Inclusion, 8(1), 86-89.

Clasen, J., \& Clegg, D. (2007). Levels and levers of conditionality: Measuring change within welfare states. In J. Clasen \& N. A. Siegel (Eds.), Investigating welfare state change: The 'dependent variable problem' in comparative analysis (pp. 166-197). Cheltenham: Edward Elgar.

Dobrotić, I., \& Blum, S. (2019). A social right: Access to leave and its relation to parents' labour market position. In P. Moss, A.-Z. Duvander, \& A. Koslowski (Eds.), Parental leave and beyond: Recent international developments, current issues and future directions (pp. 261-282). Bristol: Policy Press.

Dobrotić, I., \& Blum, S. (2020). Inclusiveness of parentalleave benefits in twenty-one European countries: Measuring social and gender inequalities in leave eligibility. Social Politics: International Studies in Gender, State \& Society, 27(3), 588-614.

Doucet, A. (2021). Socially inclusive parenting leaves and parental benefit entitlements: Rethinking care and work binaries. Social Inclusion, 9(2), 227-237.

Esping-Andersen, G. (1990). The three worlds of welfare capitalism. Princeton, NJ: Princeton University Press.

European Institute for Gender Equality. (2020). Eligibility for parental leave in EU member states. Luxembourg: Publications Office of the European Union.

Koslowski, A. (2021). Capturing the gender gap in the scope of parenting related leave policies across nations. Social Inclusion, 9(2), 250-261.

Koslowski, A., Blum, S., Dobrotić, I., Kaufman, G., \& Moss, P. (2020). (Eds.). International review of leave policies and research 2020. Hagen: Fakultät für Kultur- und Sozialwissenschaften. Retrieved http:// www.leavenetwork.org/lp_and_r_reports

Kurowska, A. (2021). The Contextualized Inclusiveness of Parental Leave Benefits. Social Inclusion, 9(2), 262-274.

Marynissen, K., Wood, J., \& Neels, K. (2021). Mothers and parental leave in Belgium: Social inequalities in eligi- bility and uptake. Social Inclusion, 9(2), 325-337.

McKay, L., Mathieu, S., \& Doucet, A. (2016). Parentalleave rich and parental-leave poor: Inequality in Canadian labour market based leave policies. Journal of Industrial Relations, 58(4), 543-562.

Moring, A., \& Lammi-Taskula, J. (2021). Parental leave reforms in Finland 1977-2019 from a diversity perspective. Social Inclusion, 9(2), 338-349.

Nygård, M., \& Duvander, A.-Z. (2021). Social inclusion or gender equality? Political discourses on parental leave in Finland and Sweden. Social Inclusion, 9(2), 300-312.

O'Brien, M. (2009). Fathers, parental leave policies, and infant quality of life: International perspectives and policy impact. ANNALS of the American Academy of Political and Social Science, 624(1), 190-213.

Orloff, A. S. (1993). Gender and the social rights of citizenship: The comparative analysis of gender relations and welfare states. American Sociological Review, 58(3), 303-328.

Otto, A., Bartova, A., \& Van Lancker, W. (2021). Measuring the Generosity of Parental Leave Policies. Social Inclusion, 9(2), 238-249.

Ray, R., Gornick, J. C., \& Schmitt, J. (2010). Who cares? Assessing generosity and gender equality in parental leave policy designs in 21 countries. Journal of European Social Policy, 20(3), 196-216.

Rostgaard, T., \& Ejrnæs, A. (2021). How different parental leave schemes create different take-up patterns: Denmark in Nordic comparison. Social Inclusion, 9(2), 313-324.

Son, K., \& Böger, T. (2021). The inclusiveness of maternity leave rights over 120 years and across five continents. Social Inclusion, 9(2), 275-287.

Uzunalioglu, M., Valentova, M., O’Brien, M., \& Genevois, A.-S. (2021). When does expanded eligibility translate into increased take-up? An examination of parental leave policy in Luxembourg. Social Inclusion, 9(2), 350-363.

Whitehouse, G., \& Nakazato, H. (2021). Dimensions of social equality in paid parental leave policy design: comparing Australia and Japan. Social Inclusion, 9(2), 288-299.

Wong, E., Jou, J., Raub, A., \& Heymann, S. S. (2019). Comparing the availability of paid parental leave for samesex and different-sex couples in 34 OECD countries. Journal of Social Policy, 49(3), 525-545.

\section{About the Authors}

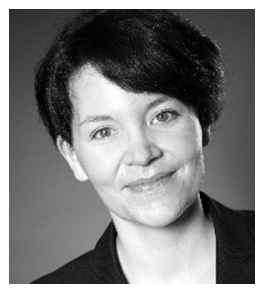

Sonja Blum is a Senior Lecturer and Researcher at the FernUniversität in Hagen (University of Hagen), and Fellow at the KU Leuven Public Governance Institute. Her specialization is in public policy and comparative social policy. She is co-editor of the Routledge Handbook of European Welfare Systems (2020, with J. Kuhlmann and K. Schubert) and has published in journals such as Social Politics, Social Policy \& Administration, Policy Studies, Policy and Society, European Societies and European Policy Analysis. 
Ivana Dobrotić is Marie Curie Fellow at the University of Oxford, Department of Social Policy and Intervention, running the project "Social and Gender Inequalities in Care: Childcare-Related Policies and Parenting Practices in the Post-Yugoslav Countries and the Role of Policy Ideas." She is also affiliated as an Associate Professor of Comparative Social Policy at the University of Zagreb. She has published in journals such as Social Politics, Social Policy \& Administration, European Societies, Europe-Asia Studies and International Journal of Sociology \& Social Policy. 